\title{
触 New Disease Reports \\ First report of Tomato brown rugose fruit virus on tomato in Egypt
}

\author{
M.A. Amer ${ }^{1,2 *}$ and S.Y. Mahmoud ${ }^{3,4}$ \\ ${ }^{1}$ Plant Protection Department, College of Food and Agriculture Sciences, King Saud University, P. O. Box 2460, Riyadh \\ 11451, Saudi Arabia ; ${ }^{2}$ Viruses and Phytoplasma Research Department, Plant Pathology Research Institute, Agricultural \\ Research Center, Egypt ; ${ }^{3}$ Agricultural Microbiology Department, Faculty of Agriculture, Sohag University, P.O. Box 83523, \\ Sohag, Egypt ; ${ }^{4}$ Biology Department, College of Sciences, Hafr Al-Batin University, P.O. Box 1803, Hafr Al-Batin 31991, \\ Saudi Arabia
}

*E-mail: mamaamery@yahoo.com

Received: 02 Apr 2020. Published: 30 Apr 2020. Keywords: DAS-ELISA, RT-PCR, sequencing, Tobamoviruses, ToBRFV

In June 2019, leaf samples from hybrid tomato (Solanum lycopersicum cv. Elquds E448) were collected from four regions in Fayoum and Ismailia Governorates, Egypt. Twenty samples were collected from plants with viral symptoms and nine from asymptomatic plants. The diseased samples had mosaics, deformation and necrosis on the leaves (Fig. 1), and discoloration and deformations on fruits (Fig. 2). Samples were tested by DAS-ELISA (LOEWE ${ }^{\circledR}$, Germany) for the presence of viruses that induce similar symptoms on tomato plants. Of the diseased samples, four tested positive for Tomato spotted wilt virus (TSWV), three each for Pepino mosaic virus and Tomato mosaic virus (ToMV), two for Tomato chlorosis virus, six for Tomato brown rugose fruit virus (ToBRFV) antisera, and three samples had a mixed infection with TSWV and ToBRFV. The ToBRFV antisera gave a weak cross reaction with ToMV.

Sap transmission using a ToBRFV-positive tomato isolate gave systemic mosaic symptoms on tomato, and chlorotic local lesions on the inoculated leaves of both Nicotiana tabacum and Chenopodium amaranticolor, indicating the presence of a tobamovirus. For confirmation, primers R-4718 / F-3666 (Luria et al., 2017), and TOBRFV-F2: 5'-GACCAACCAGAGTCTTCCTATACTCGGA-3'/ ToBRFV-R2: 5'CGGGTCCTTTTACTGGTGTCGAGAGATATG-3' (obtained from Prof. N. Salem, The University of Jordan) were used for molecular detection of tobamoviruses and ToBRFV, respectively. Six of the 20 samples yielded amplicons of the expected size for tobamoviruses (c. $1050 \mathrm{bp}$ ) and ToBRFV (c. 870 bp). Tomato mottle mosaic virus (ToMMV) was not detected in any of the samples using the specific primers (ToMMV-F and ToMMV-R) described by Sui et al., 201). RT-PCR products obtained from partial nucleotide sequence of the RNA-dependent RNA polymerase region from four ToBRFV isolates were purified and sequenced in both directions. The partial nucleotide sequence of these isolates was determined and submitted to GenBank (Accession Nos. MT227801-MT227802 for Ismailia isolates [Eg1 \& Eg 2] and MT227803-MT227804 for Fayoum isolates [Eg $3 \& \mathrm{Eg} \mathrm{4])}$. The nucleotide sequence for the Egyptian isolates shared 92.2-94.4\% identity with tomato isolates from Palestine (MN013187 and MN013188), Germany (MK133093 and MK133095), United Kingdom (MN182533), Israel (KX619418), Jordan (KT383474), Italy (MN167466) and Mexico (MK319944), and a pepper isolate from Jordan (MK648157). A phylogenetic tree (Fig. 3) revealed genetic variability between Egyptian isolates and isolates from different countries.

This is the first report of ToBRFV infecting tomato in Egypt and the ease with which it is mechanically transmitted may explain its rapid emergence around the world.

\section{References}

1. Luria N, Smith E, Reingold V, Bekelman I, Lapidot M, Levin I, Elad N, Tam Y, Sela N, Abu-Ras A, Ezra N, Haberman A, Yitzhak L, Lachman O, Dombrovsky A, 2017. A new Israeli Tobamovirus isolate infects tomato plants harboring Tm-22 resistance genes. PLOS ONE 12, e0170429. http://dx.doi.org/10.1371/journal.pone.0170429

2. Sui X, Zheng Y, Li R, Padmanabhan C, Tian T, Groth-Helms D, Keinath AP, Fei Z, Wu Z, Ling KS, 2017. Molecular and biological characterization of Tomato mottle mosaic virus and development of RT-PCR detection. Plant Disease 101, 704-711. http://dx.doi.org/10.1094/PDIS-10-16-1504-RE

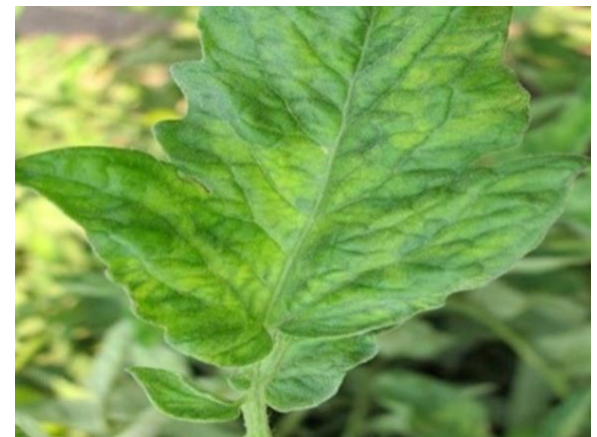

Figure 1

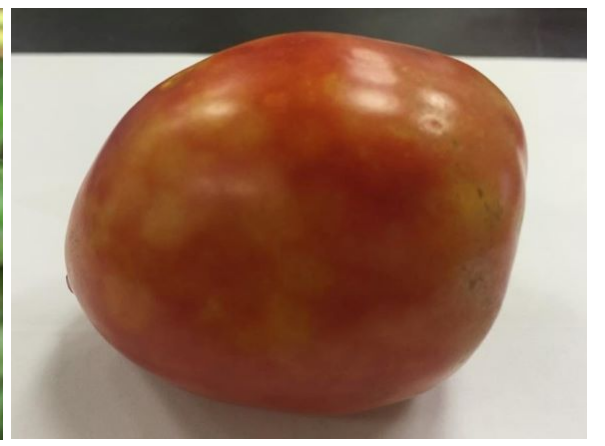

Figure 2

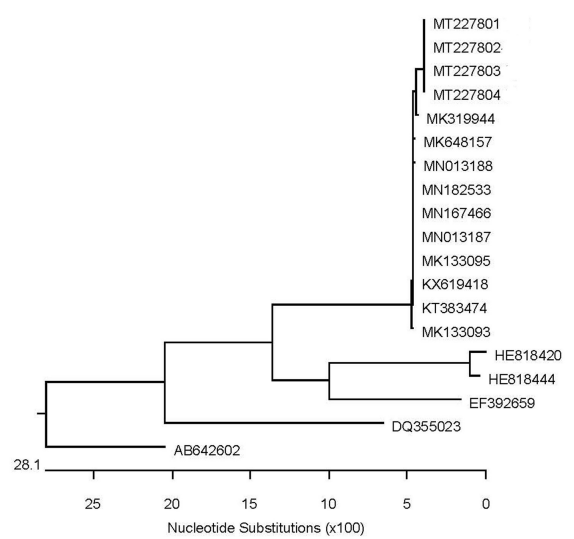

Figure 3

To cite this report: Amer MA, Mahmoud SY, 2020. First report of Tomato brown rugose fruit virus on tomato in Egypt. New Disease Reports 41, 24. http://dx.doi.org/10.5197/j.2044-0588.2020.041.024 